\title{
Supportive care needs and health-related quality of life among Chinese lung cancer survivors
}

\author{
Dorothy Ngo-Sheung Chan ${ }^{1}$, Kai-Chow Choi $^{1}$, Carmen Wing-Han Chan ${ }^{1}$, \\ Rayman Wai-Man Wan ${ }^{2}$, Suzanne So-Shan Mak ${ }^{2}$, Eliza Mi-Ling Wong ${ }^{1}$, Sek-Ying Chair ${ }^{1}$, \\ Winnie Kwok-Wei So ${ }^{1 \#}$
}

\footnotetext{
${ }^{1}$ The Nethersole School of Nursing, The Chinese University of Hong Kong, Hong Kong, China;

\#Corresponding Author: winnieso@cuhk.edu.hk

${ }^{2}$ Department of Clinical Oncology, Prince of Wales Hospital, Hong Kong, China
}

Received 20 June 2012; revised 28 July 2012; accepted 15 August 2012

\begin{abstract}
Purpose: The purpose of this study was to explore the supportive care needs and health-related quality of life (HRQoL) of lung cancer survivors, and to identify the association between patient characteristics, HRQoL and supportive care needs. Method: This was a sub-study of a larger scale survey of cancer survivors' supportive care needs. A total of $\mathbf{4 8}$ lung cancer survivors were recruited from a regional teaching hospital, and a three-part structured questionnaire was used to collect 1) socio-demographic and clinical characteristics, 2) supportive care needs and 3) health-related quality of life data. Results: The three most commonly reported unmet needs were all in the health-system information domain: 1) being informed about your results as soon as possible (58\%), 2) being informed about cancer which is under control or diminishing (50\%), and 3 ) being informed about things you can do to help yourself get well (46\%). The second most common unmet need domain was access to healthcare and ancillary support services. The survivors generally reported satisfactory HRQoL. However, household income and unmet physical and psychological needs were independently associated with HRQoL among these survivors. Conclusion: The high unmet needs in the health-system information area call for a review of the content and amount of information provided to lung cancer survivors. In addition, more attention should be given to lung cancer survivors with low incomes but high physical and psychological unmet needs, who require appropriate follow-up and long-term care
\end{abstract}

*Funding statement: This study was funded by the Chinese University of Hong Kong. of a physical, social and psychological kind.

Keywords: Supportive Care Needs; Health-Related Quality of Life; Lung Cancer Survivor

\section{INTRODUCTION}

Lung cancer is the commonest type of cancer in Hong Kong and worldwide. It accounts for $12.7 \%$ of all cancers [1]. Advances in treatment modalities have led to a steady increase in survival, with an overall five-year relative survival rate of $15.9 \%$ at all stages, which is still comparatively lower than with other cancer types [2]. During the survival period, survivors often suffer from different post-treatment hardships such as physical and psychological distress, decreased physical functioning and lowered engagement in moderate and strenuous activities $[3,4]$. The presence of these multiple post-treatment hardships leads to an increase in different supportive care needs affecting survivors' HRQoL [5,6].

Information on such care needs and HRQoL can prove invaluable to healthcare providers when planning appropriate long-term follow-up care. Several studies have been carried out to examine these needs, survivors reporting that they had high unmet supportive care needs in the health-system and information and psychological areas, in patient care and support, and in physical and daily living [7-9]. Compared with survivors of other cancer types, it was found that lung cancer survivors experienced higher unmet supportive care needs in psychological, physical and daily living areas [7].

Apart from supportive care needs, lung cancer survivors often exhibited more clinically significant problemsdyspnea, coughing and chest wall pain than the general population [6,10]. Even long-term survivors still experienced clinically significant dyspnea, fatigue and pain [11], with a poorer HRQoL as a result [6,11]. Additionally, previous findings from studies conducted in North America 
and Europe have shown that factors such as old age, male, low income, extent of resection, squamous cell carcinoma and adjuvant therapy, and high fatigue and pain scores are associated with poorer HRQoL [11-13].

In Hong Kong, lung cancer accounted for $16.8 \%$ of all cancers in 2009 [14]. It remains a devastating disease and imposes significant burdens on survivors and family members, but little is known about Hong Kong Chinese survivors' supportive care needs and HRQoL after cancer treatment.

The aims of the study are to explore the needs and HRQoL of lung cancer survivors and to examine the association between these and patient characteristics. The findings can then be used to inform changes in healthcare and social services for this group of patients.

\section{METHODS}

This was a sub-study of a larger scale survey of crosssectional supportive care needs conducted in the period from 2010 to 2011 [15]. Eligible lung cancer survivors were recruited from a regional teaching hospital. Inclusion criteria for recruitment were Chinese patients who 1) were 18 or above at the time of diagnosis, 2) were diagnosed with primary cancer, 3 ) had completed all cancer treatment within the last year, and 4) were literate in Chinese. Those who 1) had a history of psychiatric disorder, 2) suffered from metastatic brain disease, or 3) had any other type or recurrence of cancer were excluded from the study.

\subsection{Procedures}

Permission to conduct the study was obtained from the internal review board of the study institution. A research assistant approached potential subjects at the out-patient clinic; written consent to participation was obtained before the survey, and data were collected in face-to-face interviews. Medical records were reviewed by the research staff to collect demographic and clinical characteristics.

\subsection{Data Collection}

A structured questionnaire with three parts was used to collect 1) socio-demographic and disease characteristics, 2) supportive care needs and 3) health-related quality of life data.

\subsubsection{Socio-Demographic and Disease Characteristics}

The following socio-demographic and disease characteristics were collected: age, gender, marital status, educational level, employment status, monthly household income, religious belief, family history of cancer, coexisting disease, stage of the disease, time since diagnosis and number of cancer treatment received.

\subsubsection{Supportive Care Needs}

The validated Chinese version of the Supportive Care Needs Survey Form (SCNS-SF34) and Supplementary Module of Access to Healthcare Services [16] were adopted to assess the participants' needs. The SCNSSF34 measures five dimensions: 1) physical/daily living (5 items), 2) psychological state (10 items), 3) patient care and support (5 items), 4) sexuality (3 items), and 5) health systems and information needs (11 items). Participants were asked to indicate, for each item, their level of need for help over the past month, measured on a five-point scale $(1=$ no need $/$ not applicable, $2=$ no need/satisfied, 3 = low need, $4=$ moderate need and $5=$ high need). Sub-scale scores on the five dimensions were calculated by summing individual item scores and rescaling to a 0 - 100 range, with higher scores indicating a greater extent of the underlying needs dimension. Individual items on the SCNS-SF34 or supplementary module can also be divided into "no need" and "some-to-high need" to assess individual unmet needs.

\subsubsection{Health-Related Quality of Life}

The Chinese version of the Functional Assessment of Cancer Therapy-General version FACT-G (Ch) was used to examine the effect of cancer and its treatment on the HRQoL of the participants. This is a validated 28-item questionnaire with four domains: physical, emotional, social and functional well-being, with each item rated on a five-point scale ( $0=$ not at all; $1=$ a little bit; 2 = somewhat; 3 = quite a bit; 4 = very much). Both total and sub-scale scores for the well-being dimension are measured, higher scores indicating better functional status.

\subsection{Data Analysis}

Skewed continuous variables and normal-like distributed variables were respectively presented as medians (inter-quartile ranges) and means (standard deviations). Categorical data were presented as frequencies (percentages). Normality of the continuous variables was assessed using the skewness and kurtosis statistic and graphically by Q-Q plot. The variables, travelling time to hospital and time since diagnosis, were natural logtransformed to correct their skewness before being entered into the analysis. Univariate analyses of the association between the total score on FACT-G and each of the participant characteristics listed in Table $\mathbf{1}$ and the subscale scores in each of the SCNS-SF34 domains were assessed using the Student's t-test, one-way ANONA or Pearson correlation coefficient, as appropriate. Variables with $\mathrm{p}<0.25$ in univariate analyses were selected as candidate variables for stepwise multivariable regression to delineate variables independently associated with the 
Table 1. Socio-demographic and disease characteristics of the study sample $(n=48)$.

\begin{tabular}{|c|c|}
\hline & Mean (SD) / median (IQR) / n (\%) \\
\hline \multicolumn{2}{|l|}{ Socio-demographic characteristics } \\
\hline Age (years) ${ }^{\dagger}$ & $61.0(9.2)$ \\
\hline \multicolumn{2}{|l|}{ Sex } \\
\hline Male & $36(75.0 \%)$ \\
\hline Female & $12(25.0 \%)$ \\
\hline \multicolumn{2}{|l|}{ Marital status } \\
\hline Single/divorced/widowed & $8(16.7 \%)$ \\
\hline Married/cohabitating & $40(83.3 \%)$ \\
\hline \multicolumn{2}{|l|}{ Educational level } \\
\hline No formal education/primary & $22(45.8 \%)$ \\
\hline Secondary or above & $26(54.2 \%)$ \\
\hline \multicolumn{2}{|l|}{ Employment status } \\
\hline Unemployed/retired/homemaker & $44(91.7 \%)$ \\
\hline Employed & $4(8.3 \%)$ \\
\hline \multicolumn{2}{|l|}{ Household monthly income (HK\$) } \\
\hline$\leq 10,000$ & $30(62.5 \%)$ \\
\hline $10,001-30,000$ & $14(29.2 \%)$ \\
\hline$>30,000$ & $4(8.3 \%)$ \\
\hline Time travelling from home to hospital (minutes) ${ }^{\psi}$ & $42(30-60)$ \\
\hline \multicolumn{2}{|l|}{ Disease characteristics } \\
\hline Time since diagnosis (months) ${ }^{\psi}$ & $12(10-18)$ \\
\hline \multicolumn{2}{|l|}{ Stage of disease } \\
\hline$\leq \mathrm{II}$ & $13(27.7 \%)$ \\
\hline$\geq$ III & $34(72.3 \%)$ \\
\hline \multicolumn{2}{|l|}{ Number of cancer treatments } \\
\hline 1 & $10(20.8 \%)$ \\
\hline$\geq 2$ & 38 (79.2\%) \\
\hline \multicolumn{2}{|l|}{ Any co-existing disease } \\
\hline No & 29 (60.4\%) \\
\hline Yes & 19 (39.6\%) \\
\hline \multicolumn{2}{|l|}{ Family history of cancer } \\
\hline No & 27 (56.3\%) \\
\hline Yes & $21(43.8 \%)$ \\
\hline
\end{tabular}

Data marked with ${ }^{\dagger}$ are presented as means (standard deviations) and with ${ }^{\psi}$ as medians (interquartile range), all others as frequencies (\%).

quality of life score. All analyses were performed using SPSS 18.0 (SPSS Inc, Chicago), and all tests were twosided, with a p-value of $<0.05$ considered statistically significant.

\section{RESULTS}

A total of 48 Hong Kong lung cancer patients who had finished their treatment no more than a year earlier were recruited to the study. The participants were aged from 34 to 80 , with a mean of $61.0 \pm 9.2$, and $75 \%$ were male. Detailed demographic and disease characteristics are given in Table 1.

\subsection{Health-Related Quality of Life (FACT-G) and Supportive Care Needs (SCNS-SF34)}

The sub-scale and total scores for FACT-G and SCNS-SF34 are given in Table 2. There was an overall mean score of 84 (SD: 15.3, range: 1 - 108) on HRQoL. The unmet needs scores varied from 2.6 to 27.5 (range 1 -10) across five domains.

Percentages of unmet needs of all individual items on SCNS-SF34 and supplementary module are listed in Table 3 . The three most commonly reported were all in the health system and information domain: being informed 
Table 2. Health-related quality of life and supportive care needs of the study sample.

\begin{tabular}{lc}
\hline & Mean (SD) \\
\hline Health-related quality of life (FACT-G) & \\
Physical well-being [range: 0 - 28] & $23.1(4.8)$ \\
Social/family well-being [range: 0 - 28] & $22.0(5.6)$ \\
Emotional well-being [range: 0 - 24] & $20.4(4.1)$ \\
Functional well-being [range: 0 - 28] & $18.8(5.8)$ \\
Total score [range: 0 - 108] & $84.3(15.3)$ \\
Supportive care needs (SCN-SF34) & \\
Physical [range: 0 - 100] & $20.5(21.7)$ \\
Psychological [range: 0 - 100] & $14.5(18.6)$ \\
Sexual [range: 0 - 100] & $2.6(6.0)$ \\
Patient care [range: 0 - 100] & $14.2(14.9)$ \\
Health system and information [range: 0 - 100] & $27.5(20.4)$ \\
\hline
\end{tabular}

The FACT-G scales were scored so that larger values correspond to a better underlying dimension of health-related quality of life, whereas a higher SCN-SF34 subscale score indicates a larger underlying domain of supportive care need.

Table 3. Some unmet supportive care needs-individual items in SCN-SF34 and the supplementary module-among Hong Kong cancer patients.

\begin{tabular}{|c|c|}
\hline Some unmet supportive care needs & $\mathrm{n}(\%)$ \\
\hline \multicolumn{2}{|l|}{ Physical } \\
\hline At least one of the above unmet needs & $20(41.7 \%)$ \\
\hline Not being able to do the things you used to do & $12(25.0 \%)$ \\
\hline Pain & $11(22.9 \%)$ \\
\hline Feeling unwell a lot of the time & $10(20.8 \%)$ \\
\hline Work around the home & $9(18.8 \%)$ \\
\hline Lack of energy/tiredness & $9(18.8 \%)$ \\
\hline \multicolumn{2}{|l|}{ Psychological } \\
\hline At least one of the above unmet needs & $16(33.3 \%)$ \\
\hline Worry that the results of treatment are beyond your control & $10(20.8 \%)$ \\
\hline Uncertainty about the future & $9(18.8 \%)$ \\
\hline Fears about the cancer spreading & $8(16.7 \%)$ \\
\hline Concerns about the worries of those close to you & $6(12.5 \%)$ \\
\hline Feelings about death and dying & $6(12.5 \%)$ \\
\hline Learning to feel in control of your situation & $6(12.5 \%)$ \\
\hline Anxiety & $5(10.4 \%)$ \\
\hline Keeping a positive outlook & $4(8.3 \%)$ \\
\hline Feeling down or depressed & $3(6.3 \%)$ \\
\hline Feelings of sadness & $3(6.3 \%)$ \\
\hline \multicolumn{2}{|l|}{ Sexuality } \\
\hline Changes in sexual feelings & 0 \\
\hline Changes in sexual relationships & 0 \\
\hline Being given information about sexual relationships & 0 \\
\hline At least one of the above unmet needs & 0 \\
\hline \multicolumn{2}{|l|}{ Patient care } \\
\hline At least one of the above unmet needs & $24(50.0 \%)$ \\
\hline Hospital staff attending promptly to your physical needs & $16(33.3 \%)$ \\
\hline Reassurance by medical staff that the way you feel is normal & $11(22.9 \%)$ \\
\hline More choice about which cancer specialists you see & $8(16.7 \%)$ \\
\hline
\end{tabular}




\section{Continued}

\begin{tabular}{|c|c|}
\hline Hospital staff acknowledging, and showing sensitively to, your feelings and emotional needs & $6(12.5 \%)$ \\
\hline More choice about which hospital you attend & $4(8.3 \%)$ \\
\hline \multicolumn{2}{|l|}{ Health system and information } \\
\hline At least one of the above unmet needs & $35(72.9 \%)$ \\
\hline Being informed about your test results as soon as feasible & $28(58.3 \%)$ \\
\hline Being informed about cancer which is under control or diminishing (that is, remission) & $24(50.0 \%)$ \\
\hline Being informed about things you can do to help yourself get well & $22(45.8 \%)$ \\
\hline Being given explanations of those tests for which you would like explanations & $20(41.7 \%)$ \\
\hline $\begin{array}{l}\text { Being adequately informed about the benefits and side-effects of treatments before } \\
\text { you choose to have them }\end{array}$ & $18(37.5 \%)$ \\
\hline $\begin{array}{l}\text { Having one member of hospital staff you can talk to about all aspects of } \\
\text { your condition, treatment and follow-up }\end{array}$ & $13(27.1 \%)$ \\
\hline Being treated in a hospital or clinic that is as physically pleasant as possible & $12(25.0 \%)$ \\
\hline Being treated like a person and not just another case & $8(16.7 \%)$ \\
\hline $\begin{array}{l}\text { Having access to professional counselling (e.g., psychologist, social worker, } \\
\text { counsellor, nurse specialist) if you, family or friends need it }\end{array}$ & $7(14.6 \%)$ \\
\hline $\begin{array}{l}\text { Being given information (written, diagrams, drawings) about aspects of } \\
\text { managing your illness and its side-effects at home }\end{array}$ & $7(14.6 \%)$ \\
\hline Being given written information about the important aspects of your care & $5(10.4 \%)$ \\
\hline \multicolumn{2}{|l|}{ Supplementary module } \\
\hline At least one of the above unmet needs & $34(70.8 \%)$ \\
\hline Monetary allowance for travel, treatment and equipment expenses & $21(43.8 \%)$ \\
\hline Comfortable waiting room & $10(20.8 \%)$ \\
\hline Food and drink available in or near the clinic waiting room & $9(18.8 \%)$ \\
\hline Transport service to and from the hospital or clinic & $8(16.7 \%)$ \\
\hline Brochures about services and benefits for patients with cancer & $8(16.7 \%)$ \\
\hline 24-hour telephone support and cancer advisory service & $8(16.7 \%)$ \\
\hline Drop-in counselling and support service & $5(10.4 \%)$ \\
\hline Library of books and videos about cancer and related issues & $5(10.4 \%)$ \\
\hline $\begin{array}{l}\text { Counselling services (e.g. counsellor, psychologist, social worker, nurse } \\
\text { specialist) at the hospital or clinic for your family/ partner }\end{array}$ & $3(6.3 \%)$ \\
\hline Easy car parking at the hospital or clinic & $3(6.3 \%)$ \\
\hline Home nursing service (e.g. nurse specialist visiting service) & $3(6.3 \%)$ \\
\hline Home cleaning service (e.g. house cleaner service) & $3(6.3 \%)$ \\
\hline Respite care & $2(4.2 \%)$ \\
\hline Relaxation classes & $2(4.2 \%)$ \\
\hline Child-minding at the hospital or clinic & 0 \\
\hline
\end{tabular}

about 1) your results as soon as possible (58\%), 2) cancer which is under control or diminishing (50\%), and 3) things you can do to help yourself get well (46\%). In fact, most participants (73\%) reported at least one unmet need in relation to healthcare information, and about $71 \%$ had at least one unmet need related to access to the healthcare and ancillary support services domain. In the physical and psychological domains, pain, feeling unwell, fatigue, worry about treatment results and uncertainty about the future often constituted unmet needs. The proportions of at least one unmet need in the patient care, physical, psychological and sexuality domains were respectively 50\%, 42\%, 33\% and 0\% (Table 3).

\subsection{Association between HRQoL, Patient Characteristics and Supportive Care Needs}

Stepwise multivariable regression analyses, using those variables with $\mathrm{p}$ values $<0.25$ in univariate analyses as candidate variables, revealed that household income and physical and psychological unmet needs were independently associated with HRQoL among the lung cancer survivors. Patients with medium and high household incomes had significantly higher total FACT-G scores than those with low incomes (regression coefficient = $12.7, \mathrm{p}<0.001$ for those with middle incomes; regression coefficient $=14.0, \mathrm{p}=0.01$ for those with high in- 
comes). Patients with higher scores in the physical or psychological dimensions of SCNS-SF34 were associated with lower total FACT-G scores (regression coefficient $=-0.22(\mathrm{p}=0.007)$ and $-0.43(\mathrm{p}<0.001)$ for physical and psychological dimensions respectively).

Other disease characteristics (e.g. stage of cancer, time since diagnosis) were not associated with HRQoL. Table 4 shows the association between HRQoL and other variables.

Table 4. Association between heath-related quality of life (FACT-G) and other variables.

\begin{tabular}{|c|c|c|c|c|c|}
\hline \multirow[b]{2}{*}{ Disease characteristics } & \multicolumn{2}{|l|}{ Univariate analysis } & \multicolumn{3}{|c|}{ Multivariate analysis } \\
\hline & Mean (SD)/correlation coefficient ${ }^{\#}$ & p-value & $\mathrm{B}$ & SE & p-value \\
\hline \multicolumn{6}{|l|}{ Socio-demographic characteristics } \\
\hline Age (years) ${ }^{\dagger}$ & -0.173 & 0.239 & NS & NS & NS \\
\hline \multicolumn{6}{|l|}{ Sex } \\
\hline Male & $84.7(13.5)$ & 0.810 & - & - & - \\
\hline Female & $83.2(20.5)$ & & & & \\
\hline \multicolumn{6}{|l|}{ Marital status } \\
\hline Single / divorced / widowed & $82.0(15.2)$ & 0.642 & - & - & - \\
\hline Married / cohabitating & $84.8(15.5)$ & & & & \\
\hline \multicolumn{6}{|l|}{ Educational level } \\
\hline No formal education / primary & $80.5(15.2)$ & 0.116 & NS & NS & NS \\
\hline Secondary or above & $87.5(15.0)$ & & & & \\
\hline \multicolumn{6}{|l|}{ Employment status } \\
\hline Unemployed / retired / homemaker & $82.8(15.1)$ & $<0.001$ & NS & NS & NS \\
\hline \multicolumn{6}{|l|}{ Household monthly income (HK\$) } \\
\hline$\leq 10,000$ & $80.5(14.6)$ & 0.037 & (ref) & & \\
\hline $10,001-30,000$ & $88.4(15.7)$ & & 12.667 & 3.180 & $<0.001$ \\
\hline$>30,000$ & $98.8(6.1)$ & & 13.997 & 5.214 & 0.010 \\
\hline \multicolumn{6}{|l|}{ Living alone } \\
\hline No & $85.1(15.0)$ & 0.189 & NS & NS & NS \\
\hline Yes & $73.0(19.1)$ & & & & \\
\hline Time travelling from home to hospital (minutes) ${ }^{\dagger}$ & -0.037 & 0.804 & - & - & - \\
\hline \multicolumn{6}{|l|}{ Disease characteristics } \\
\hline Time since diagnosis (months) $^{\dagger}$ & 0.199 & 0.175 & NS & NS & NS \\
\hline \multicolumn{6}{|l|}{ Stage of disease } \\
\hline$\leq \mathrm{II}$ & $88.0(13.1)$ & 0.304 & & & \\
\hline$\geq$ III & $82.8(16.2)$ & & & & \\
\hline$\geq 2$ & $86.9(13.6)$ & & & & \\
\hline \multicolumn{6}{|l|}{ Any co-existing disease } \\
\hline No & $85.6(15.4)$ & 0.490 & - & - & - \\
\hline Yes & $82.4(15.4)$ & & & & \\
\hline \multicolumn{6}{|l|}{ Cancer is under control or diminishing } \\
\hline Yes & $85.5(13.8)$ & 0.474 & - & - & - \\
\hline No/unsure & $82.1(18.2)$ & & & & \\
\hline \multicolumn{6}{|l|}{ Family history of cancer } \\
\hline No & $82.8(16.7)$ & 0.442 & - & - & - \\
\hline Yes & $86.3(13.5)$ & & & & \\
\hline \multicolumn{6}{|l|}{ Supportive care needs } \\
\hline Physical & -0.569 & $<0.001$ & -0.218 & 0.077 & 0.007 \\
\hline Psychological & -0.624 & $<0.001$ & -0.426 & 0.089 & $<0.001$ \\
\hline Sexual & -0.019 & 0.896 & - & - & - \\
\hline Patient care & -0.454 & 0.001 & NS & NS & NS \\
\hline Health system and information & -0.417 & 0.003 & NS & NS & NS \\
\hline
\end{tabular}

\#Pearson's correlation coefficients between the independent and outcome variables are presented for continuous independent variables, whereas means (standard deviations) of the outcome variables are presented for categorical independent variables; ${ }^{\dagger}$ log-transformed to correct skewness when entered into statistical analyses; ref: reference group of the independent categorical variables analysed by creating dummy variables; B: regression coefficient; SE: standard error of the regression coefficient; NS: not statistically significant in stepwise multivariable regression; -: not entered into multivariable regression (univariate analysis of $p$ value $\geq 0.2$ ). 


\section{DISCUSSION}

\subsection{Unmet Supportive Care Needs}

A recent study [17] shows that $70 \%$ - $90 \%$ of patients wanted to seek help from others regarding their informational needs. In the present study, the results underline the fact that lung cancer survivors in Hong Kong have unmet needs for health information. Survivors rated health system and information as their top unmet needs, while in Sander et al. [9] and Li and Girdis [7], physical and daily living and psychological needs are respectively ranked top. The same result was noted in the proportions of at least one unmet need in each domain when comparing the present and previous studies [9]. In addition, within the health system and information domain, over half of the respondents indicated that they had highest unmet needs in "being informed about your results as soon as possible" while in the Sanders et al. study 34\% of respondents cited "being informed about things one could do to help get well" as the most common unmet need.

These findings could be due to different resources being allocated by the healthcare systems of different countries. Lung cancer patients always find health system and information important no matter which phase they are in [18]. Starting from cancer diagnosis to posttreatment phase, healthcare providers have provided continuous disease- and treatment-related informational support to lung cancer patients. However, it seems that Hong Kong patients' demand for information far exceeds its present provision. The result indicates the necessity for further improvement in the health system and information area to meet these increasing needs.

\subsection{Association between HRQoL and Patient Characteristics and Supportive Care Needs}

With respect to socio-demographic characteristics, our results show that household income is the only factor showing an association with HRQoL. Survivors with medium and high household income had significantly higher total HRQoL scores, while the reverse was observed in the low income group, consistent with the findings of a previous study [13]. In the present study, $92 \%$ of the respondents were unemployed and $63 \%$ of their household monthly income was less than $\$ 10,000$ (US\$1285). Their daily expenditure probably depended on their family or their pension, imposing financial strain on both survivors and their families. Household income is found to be closely related to employment status and earnings. According to Syse, Tretli and Kravdal [19], contracting cancer reduces patients' chances of employment by $30 \%-40 \%$, and the earnings of those in employment by $26 \%$. Lung cancer patients are obviously affected by a decrease in employment, which significantly affects their monthly household income and thus their HRQoL [13,19].

In the supportive care needs survey, both physical and psychological domains were found to have a significant negative association with HRQoL. In these domains, pain, fatigue, worry about treatment results and uncertainty about the future were the major issues that concerned respondents the most, consistent with a previous study's finding that fatigue and pain had the greatest impact on lowering HRQoL [20].

\section{LIMITATION}

Small sample size is the limitation of the present study as it was a sub-study of a larger scale cross-sectional study of cancer patients' supportive care needs and HRQoL. Further study including larger sample size focusing on lung cancer patients is recommended.

\section{CONCLUSION}

Lung cancer, constituting a significant proportion of all cancer types, continues to impose a significant burden on patients, survivors and healthcare systems. Understanding lung cancer survivors' supportive care needs certainly helps to enhance the follow-up healthcare service, leading to better adjustment during the survival phase, and in the long run the burden on the healthcare system will be reduced. The present study confirms the high unmet needs in the health system and information area, and shows how important it is to review and expand the information given to these survivors. Additionally, more attention should be given to survivors on low incomes but with high physical and psychological unmet needs, as they are prone to suffer a lower HRQoL.

\section{REFERENCES}

[1] IARC (2010) Globocan 2008: Fast stats. http://globocan.iarc.fr/factsheets/populations/factsheet.as p?uno $=900$

[2] Howlader, N., Noone, A.M., Krapcho, M., et al. (2009) SEER cancer statistics review 1975-2009. http://seer.cancer.gov/csr/1975_2009_pops09/

[3] Cooley, M.E., Short, T.H. and Moriary, H.J. (2003) Symptom prevalence, distress, and change over time in adults receiving treatment for lung cancer. Psycho-Oncology, 12, 694-708. doi:10.1002/pon.694

[4] Coups, E.J., Park, B.J., Feinstein, M.B., et al. (2009) Physical activity among lung cancer survivors: Changes across the cancer trajectory and associations with quality of life. Cancer Epidemiology Biomarkers and Prevention, 18, 664-672. doi:10.1158/1055-9965.EPI-08-0589

[5] Harrison, J.D., Young, J.M., Price, M.A., Butow, P.N. and Solomon, M.J. (2009) What are the unmet supportive 
care needs of people with cancer? A systematic review. Supportive Care in Cancer, 17, 1117-1128. doi:10.1007/s00520-009-0615-5

[6] Yun, Y.H., Kim, Y.A., Min, Y.H., et al. (2012) Healthrelated quality of life in disease-free survivors of surgically treated lung cancer compared with the general population. Annals of Surgery, 255, 1000-1007. doi:10.1097/SLA.0b013e31824f1e9e

[7] Li, J. and Girdis, A. (2006) Supportive care needs: Are patients with lung cancer a neglected population? Psycho-Oncology, 15, 509-516. doi:10.1002/pon.983

[8] Liao, Y.-C., Liao, W.-Y., Shun, S.-C., et al. (2011) Symptoms, psychological distress, and supportive care needs in lung cancer patients. Supportive Care in Cancer, 19, 1743-1751. doi:10.1007/s00520-010-1014-7

[9] Sanders, S.L., Bantum, E.O., Owen, J.E., et al. (2010) Supportive care needs in patients with lung cancer. Psycho-Oncology, 19, 480-489. doi:10.1002/pon.1577

[10] Sarna, L., Cooley, M.E., Brown, J.K., et al. (2010) Women with lung cancer: Quality of life after thoracotomy: A 6-month prospective study. Cancer Nursing, 33, 85-92. doi:10.1097/NCC.0b013e3181be5e51

[11] Yang, P., Cheville, A.L., Wampfler, J.A., et al. (2012) Quality of life and symptom burden among long-term lung cancer survivors. Journal of Thoracic Oncology, 7, 64-70. doi:10.1097/JTO.0b013e3182397b3e

[12] Moller, A. and Sartipy, U. (2012) Predictors of postoperative quality of life after surgery for lung cancer. Journal of Thoracic Oncology, 7, 406-411. doi:10.1097/JTO.0b013e3182398e82

[13] Le Corroller-Soriano, A.G., Bouhnk, A.-D., Preau, M., et al. (2011) Does cancer survivors' health-related quality of life depend on cancer type? Findings from a large French national sample 2 years after cancer diagnosis. European Journal of Cancer Care, 20, 132-140. doi:10.1111/j.1365-2354.2009.01160.x

[14] Hospital Authority: Hong Kong Cancer Registry (2012) Top ten cancers in 2009. http://www3.ha.org.hk/cancereg/e stat.asp

[15] So, W.K.W., Chan, C.W.H., Choi, K.C., Wan, R.W.M., Mak, S.S.S. and Chair, S.Y. (2012) Perceived unmet needs and health-related quality of life of Chinese cancer survivors at one year after treatment. Cancer Nursing, In Press.

[16] So, W.K.W., Choi, K.C., Mak, S.S.S., et al. (2011) Validation of the Chinese version of supportive care needs survey and supplementary module of access to health care services. Supportive Care in Cancer, 19, S198.

[17] Fitch, M.I. and Steele, R. (2010) Supportive care needs of individuals with lung cancer. Canadian Oncology Nursing Journal, 20, 15-22.

[18] Wiljer, D., Walton, T., Gilbert, J., et al. (2012) Understanding the needs of lung cancer patients during the prediagnosis phase. Journal of Cancer Education, 27, 494500. doi:10.1007/s13187-012-0345-0

[19] Syse, A., Tretli, S. and Kravdal, O. (2008) Cancer's impact on employment and earnings-A population-based study from Norway. Journal of Cancer Survivorship, 2, 149-158. doi:10.1007/s11764-008-0053-2

[20] Shi, Q., Smith, T.G., Michonski, J.D., et al. (2011) Symptom burden in cancer survivors 1 year after diagnosis. Cancer Survivorship, 117, 2779-2790. 